\title{
Condições de trabalho na Educação Infantil no Brasil: os desafios da profissionalização e da valorização docente
}

\section{Working conditions for Early Childhood Education in Brazil: the challenges of professionalization and teacher appreciation}

\author{
Arinalda Silva Locatelli* \\ Lívia Fraga Vieira**
}

\begin{abstract}
RESUMO
Neste artigo, apresentam-se os resultados de pesquisa cujo objetivo foi analisar as dimensões constitutivas do trabalho docente na Educação Infantil pública e sua relação com o processo de expansão das políticas educativas voltadas para esta etapa da educação básica, ocorrida nas últimas décadas, em municípios da Região Amazônica. Os dados analisados foram as respostas aos questionários aplicados a 137 sujeitos docentes (professoras e monitoras) atuantes no universo de 31 instituições públicas municipais de Educação Infantil, que atendiam crianças na faixa etária de 0 a 5 anos, do estado do Tocantins, das áreas rural e urbana dos municípios de Araguatins e Tocantinópolis. As informações sobre perfil e percepção dos sujeitos docentes sobre as suas condições de trabalho foram coletadas durante o segundo semestre do ano de 2016. O contexto analisado remete-nos a avaliar que, mesmo reconhecendo que nas últimas décadas houve avanços em relação às condições de trabalho, na dimensão estrutural e nas relações de trabalho, a consecução de uma Educação da Primeira Infância comprometida com a qualidade da educação e o bem-estar das crianças e profissionais, ainda
\end{abstract}

* Universidade Federal do Tocantins. Tocantinópolis, Tocantins, Brasil. E-mail: naldalli@ uft.edu.br. https://orcid.org/0000-0002-3573-1706.

** Universidade Federal de Minas Gerais. Faculdade de Educação. Belo Horizonte, Minas Gerais, Brasil. E-mail: liviafraga59@gmail.com. https://orcid.org/0000-0002-9036-0151. 
não se consolidou no sentido de implementar uma política sistemática de investimentos nas condições de trabalho oferecidas aos profissionais que educam e cuidam nas creches e pré-escolas.

Palavras-chave: Educação Infantil. Condições de trabalho. Valorização docente. Região Amazônica. Tocantins.

\begin{abstract}
In this article, we present results of a research with the objective of analyzing the constitutive dimensions of the teaching work in public early childhood education and its relation with the process of expansion of the educational policies aimed at this stage of basic education that occurred in the last decades in municipalities of the Amazon region. We analyzed the answers to questionnaires applied to 137 teaching subjects (teachers and monitors), working in the universe of thirty-one early childhood education institutions in the state of Tocantins, which catered to children aged 0 to 5 years within the rural and urban areas of Araguatins and Tocantinópolis. Information on the profile of teaching subjects and their perception of their working conditions was collected during the second semester of 2016. Through the analysis, we can evaluate that, even recognizing that in recent decades there have been advances in working conditions, both in terms of structural dimension and labor relations, the achievement of an early childhood education program committed to quality and the well-being of children and professionals has not yet been consolidated. There are no plans to implement a systematic policy of investing in the working conditions offered to professionals who educate and look after children in day care centers and preschools.
\end{abstract}

Keywords: Child Education. Work conditions. Teacher appreciation. Amazon region. Tocantins.

\title{
Introdução
}

A Educação Infantil no Brasil vem se configurando como um campo de trabalho e um mercado de emprego significativo sobretudo a partir dos anos 1990, com a sua institucionalização como primeira etapa da educação básica e com a implicação dos municípios na oferta pública de creches e pré-escolas.

A sua expansão se relaciona com a demanda evidente, nas nossas sociedades contemporâneas - cada vez mais urbanizadas -, de educação e cuidado de bebês e crianças pequenas em espaços não domésticos, com crescente pro- 
fissionalização. Tal demanda é determinada por mudanças sociodemográficas e por outras no âmbito das concepções sobre a infância e a primeira infância como sujeito de direitos e como ator social. Com isso emerge novas exigências profissionais e a evidência de que o direito da criança à educação depende de políticas educativas consistentes que garantam parâmetros de infraestrutura e funcionamento dos serviços, em que a presença de profissionais com formação e qualificação, são requisitos amplamente reconhecidos para a garantia da qualidade. Portanto, efetivar direitos das crianças implica garantir profissionais respeitados nos seus direitos à valorização profissional.

Este estudo se refere à docência na Educação Infantil como trabalho, o que nos remete a uma complexa discussão que aproxima o professor e a professora da classe trabalhadora de forma geral, nos termos das condições de trabalho. E como tal estaria sendo afetada por um processo de proletarização, mas que precisa ser analisado considerando as suas especificidades (JÁEN, 1991).

As condições de trabalho se referem tanto aos aspectos estruturais - como disponibilização de instalações físicas, materiais didáticos, equipamentos e meios de realização das atividades - quanto às relações que denotam o processo de trabalho e as condições de emprego, representadas pelas formas de ingresso, contratação, remuneração e carreira (OLIVEIRA; ASSUNÇÃO, 2010) que comportam traços objetivos e subjetivos. Os estudos nos permitem entender que esses dois aspectos têm como pano de fundo os tipos de relações presentes no ambiente escolar, que acontecem em terreno de tensões, conflitos, negociações, pelo fato de haver divergências entre as perspectivas docentes a respeito das condições ideais para o exercício da profissão e as perspectivas neoliberais prevalentes nas políticas educacionais atuais pautadas nas diretrizes da reforma empresarial da educação (FREITAS, 2018), o que mesmo de forma diferenciada, também afetam o contexto da Educação Infantil.

Neste artigo são apresentados os resultados de pesquisa cujo objetivo foi analisar as dimensões constitutivas do trabalho docente na Educação Infantil pública e sua relação com o processo de expansão das políticas educativas voltadas para esta etapa da educação básica, ocorrida nas últimas décadas, em municípios da Região Amazônica. As análises tiveram como fonte de dados as respostas aos questionários aplicados a 137 sujeitos docentes (professoras e monitoras) atuantes no universo de 31 instituições públicas municipais de Educação Infantil, que atendiam crianças na faixa etária de 0 a 5 anos, das áreas rural e urbana dos municípios de Araguatins e Tocantinópolis, estado de Tocantins (região do Bico de Papagaio). As informações sobre perfil e percepção dos sujeitos docentes sobre as suas condições de trabalho foram coletadas durante o segundo semestre do ano de 2016. 
Do total de respondentes, 116 eram professoras titulares das turmas, correspondendo a $84,7 \%$ dos respondentes, e 21 eram monitoras de turmas, sendo $15,3 \%$ das entrevistadas. Estavam inclusas em nossa amostra, tanto professoras que trabalham unicamente com crianças da Educação Infantil, quanto aquelas que atendiam concomitantemente a Educação Infantil e o Ensino Fundamental em salas multisseriadas/multietapas. A participação dos respondentes dos dois municípios ocorreu de forma equilibrada.

Araguatins é o $6^{\circ}$ município mais populoso entre os 139 do estado do Tocantins. Ele ocupa a $1^{\mathrm{a}}$ colocação em relação aos 25 que compõem a microrregião do Bico do Papagaio. Por sua vez, Tocantinópolis é o $9^{\circ}$ município mais populoso do estado e o $2^{\circ}$ da referida microrregião.

Com base na Sinopse Estatística divulgada pelo Inep ${ }^{1}$ (2016), a Educação Básica do Município de Tocantinópolis contava com um quantitativo de 36 escolas, sendo 20 localizadas na área urbana e 16 na área rural. Dessas, 15 pertenciam à rede municipal, 19 à rede estadual e 2 à rede privada. Vale ressaltar que das 16 escolas localizadas na área rural, 10 eram indígenas, atendendo somente do Ensino Fundamental ao Ensino Médio.

O município de Araguatins também conta com 36 escolas, sendo 21 localizadas na área rural e 15 na área urbana. Decompondo por dependência administrativa, 11 estaduais, 20 municipais, 4 privadas e 1 federal, trata-se do Instituto Federal do Tocantins - IFTO. O IFTO oferece Ensino Médio Básico, Médio Integrado, Médio Profissionalizante e Ensino Superior e atende a área rural. Do total de escolas, 5 estavam situadas em áreas de assentamento, sendo 3 municipais e 2 estaduais.

Buscou-se aqui discutir a dimensão das condições de trabalho enquanto valorização docente, a partir da questão norteadora: quais as condições de trabalho vivenciadas e percebidas pelas professoras da Educação Infantil pública tocantinense diante do processo de expansão das políticas educativas voltadas para essa etapa da educação básica?

O texto está organizado em três tópicos: a) apontamentos sobre profissionalização docente no contexto latino-americano, b) aspectos constitutivos das condições de trabalho e c) as condições de trabalho na educação da primeira infância. 


\section{Apontamentos sobre a profissionalização docente}

O exercício da profissão docente na América Latina, ao longo de sua trajetória histórica e social no último século, é demarcado pela heterogeneidade dos profissionais que exercem o magistério, pertinente aos quesitos: origem social, nível de formação, gênero, dedicação à docência.

A literatura (BERTOLDO; SANTOS, 2012; ENGUITA, 2001; FANFANI, 2007; LUDKE; BOING, 2004; POPKEWITZ, 1997; OLIVEIRA, 2010) tem colocado em tela a trajetória do magistério e as lutas pelo seu reconhecimento como uma profissão. Resguardadas as especificidades de cada contexto estudado, tais referências trazem à tona a complexidade da temática referente à identidade do trabalho docente no que tange ao processo de sua profissionalização. Nesse âmbito, Enguita (2001, p. 54) mencionou que "temos um grupo de professores, com origem e características formais de uma profissão burocrática, porém com ideal coletivo e a prática informal de uma profissão liberal". Reiterando a questão, Ludke e Boing (2004, p. 1161) mencionaram que "há consensos entre os especialistas ao conceituar profissões, mas também há certos traços incompatíveis ao se tentar aplicar esse conceito ao magistério". O dilema enunciado perpassa duas questões que se complementam e possuem vários desdobramentos: primeiro, a natureza do trabalho docente (vocação/missão ou serviço público estatal) e, em segundo lugar, as mudanças no cenário socioeconômico da América Latina que vêm afetando as relações de trabalho e têm se configurado na precarização do trabalho docente e na constituição de um novo profissionalismo (OLIVEIRA, 2018).

A respeito da primeira questão, Enguita ponderou que a categoria docente não deve buscar nem uma identidade liberal, nem burocrática, mas sim democrática, significando o compromisso com os fins da educação, que seria um serviço para e com o público, objetivando a igualdade e a participação. Ainda em sua opinião, o que designaria um professor em um sentido estrito é o seu conhecimento profissional, que, em suas palavras, denota a "[...] capacidade diagnóstica de encontrar as formas de aprendizagem e de ensino adequadas para diferentes problemas e indivíduos" (ENGUITA, 2001, p. 59).

No mesmo campo de reflexão, de acordo com Tenti Fanfani (2007), há uma tensão entre dois aspectos da identidade docente: a técnica (concebida por meio da formação, da especialização) e o social (localizado nas relações estabelecidas, na mediação entre os componentes da ação educativa). Para o autor, um novo conceito para vocação surge no cerne da profissionalização docente denominado de ethos social, ligado ao compromisso, respeito e cuidado com o outro. Este 
ethos traz à tona a necessidade de se potencializar as discussões a respeito do caráter social e político que compõem a identidade docente, em que o primeiro lembra que a docência é um trabalho coletivo, e o segundo, que está voltado para a perspectiva de transformação humana.

Consideramos importante a ponderação feita por Ludke e Boing (2004) a respeito da unidade da profissionalização com os estabelecimentos de ensino, ou seja, a identidade profissional docente está atrelada à instituição escolar, lugar onde se consolida, por meio da prática, o repertório pedagógico necessário ao exercício de sua profissão. Reitera-se assim a sua diferença com as profissões de caráter liberal que não se prendem a instituições e ratifica-se seu viés burocrático.

Em relação à segunda questão - as mudanças no contexto socioeconômico, nas relações de trabalho e a precarização do trabalho docente -, é necessário lembrar que as reformas dos anos de 1990 buscaram transferir para os sistemas educativos os pressupostos da Nova Gestão Pública (NGP), inspirados na organização do setor privado empresarial, que se implementam por meio da: descentralização, "autonomia" das instituições, o diretor como "gerente"/gestor, novos modos de regulação pelos resultados, accountability dos docentes. Tais princípios de organização do trabalho na escola são percebidos no cotidiano docente por meio de programas que buscam a aferição de resultados do desempenho discente com os testes de larga escala, a definição de mínimos curriculares e níveis de aprendizagem, avaliação da qualidade profissional dos docentes, pagamento de bonificações conforme o rendimento (VERGER; NORMAND, 2015).

Evidencia-se também que as necessidades educativas atuais não são as mesmas que marcaram a origem da profissão docente no período de estruturação dos Estados Nacionais. Essas mudanças são sentidas, por exemplo, na relação com as famílias dos discentes e com as novas tecnologias de informação. Em relação às famílias, a nova configuração social exige dos docentes uma revisão do próprio conceito de família e o cumprimento de tarefas que excedem o estritamente pedagógico. Quanto às novas tecnologias, a sua inserção no cotidiano docente pressupõe o desenvolvimento de novas habilidades e saberes, que acabam recaindo nas discussões sobre o currículo das formações docentes.

Tenti Fanfani (2007) e Ludke e Boing (2004) fazem referência à transformação da noção de trabalho, que passa de um contexto onde se tinha uma definição explícita e prescritiva das tarefas a serem desenvolvidas para uma realidade de obrigações implícitas, de investimento pessoal, cercada de incertezas e dependente da criatividade individual e coletiva. Há entre os docentes um forte sentimento de lacuna entre as expectativas e a realidade do ofício a ser desenvolvido, ocasionando situações ambivalentes em que ao mesmo tempo se sente gratificado e vivencia situações de mal-estar docente no exercício da profissão. 


\section{Aspectos constitutivos das condições de trabalho}

No cerne do debate sobre o trabalho residem pontos acerca das condições em que ele se efetiva. Tais condições abarcam a qualidade e a disponibilidade de recursos físicos, equipamentos e materiais pedagógicos, bem como as relações e processos de trabalho e a situação trabalhista, expressas nas formas de ingresso, contratação, remuneração e carreira (OLIVEIRA; ASSUNÇÃO, 2010). Dimensões objetivas e subjetivas estão assim presentes nas condições de trabalho, as quais ganham especificidades dependendo da etapa de educação básica.

Em relação aos aspectos estruturais das condições de trabalho, reportamos aqui a pesquisa "Trabalho Docente na Educação Básica no Brasil”" (TDEBB), realizada pelo Grupo de Estudos sobre Política Educacional e Trabalho Docente - TDEBB/GESTRADO em sete estados brasileiros nos anos de 2009/2010 - em que, do total de 8.795 sujeitos docentes entrevistados da Educação Básica, 1.838 eram sujeitos docentes da Educação da Primeira Infância. Mostrou-se que mais da metade das professoras de Educação Infantil entrevistadas avaliaram como regulares ou ruins fatores ambientes como ventilação e ruídos na unidade educacional. Além disso, a maioria também avaliou como regulares ou ruins quesitos como quadras de esportes, parquinhos/áreas de recreação, sala de informática, salas de convivência e repouso (VIEIRA; OLIVEIRA, 2013).

Ainda sobre os fatores estruturais, uma pesquisa acerca da saúde docente, desenvolvida por Vieira et al. (2007), evidenciou resultados em que a condição climática, aliada às questões de uso excessivo da fala e à disputa com ruídos externos à sala de aula, contribui para a ocorrência de distúrbios fônicos que acometem docentes da educação básica, como, por exemplo, a disfonia, que acarreta a diminuição da qualidade de vida da professora e, por conseguinte, interfere no aprendizado dos alunos. Além dos distúrbios de voz, as pesquisas que envolvem a temática do adoecimento docente (CODO, 1999) indicam que uma a cada quatro educadoras sofre de exaustão emocional.

A análise das relações de emprego remete à observação de duas dimensões do trabalho. A primeira dimensão, de caráter objetivo, abrange questões de regime de trabalho, piso salarial profissional, carreira docente com possibilidade de progressão funcional, concurso público de provas e títulos, formação e qualificação profissional, tempo remunerado para estudos, planejamento e avaliação (conforme assegurado no contrato de trabalho) e condições de trabalho. A segunda, subjetiva, trata do reconhecimento social, autorrealização e dignidade profissional. Esses temas figuram como fatores primordiais na efetivação de políticas de valorização docente nas pautas reivindicativas de organizações que 
representam a categoria docente, como, por exemplo, a Confederação Nacional dos Trabalhadores em Educação (CNTE).

Retomando a trajetória do magistério, Leher (2010) esclarece que as lutas em prol da sua valorização têm origem, no caso brasileiro, com o processo de massificação da escola pública, em razão dos seus efeitos de intensificação e precarização do trabalho docente. Conforme o mesmo autor, a classe docente tem procurado, desde o século XIX, organizar-se por meio de entidades representativas e criar estratégias de luta em prol da valorização de sua profissão - o que permitiu avanços significativos.

Entre os avanços conseguidos nos últimos 20 anos, podem ser mencionados: a) a inserção no art. 205 da CF/1988 da questão do Regime Jurídico Único como preceito legal ${ }^{2}$; b) a inclusão do tema também na $\mathrm{LDBEN}^{3}$ vigente, no seu art. 67; c) a criação do Fundo de Manutenção e Desenvolvimento do Ensino Fundamental e de Valorização do Magistério (FUNDEF), Lei no 9.424/96, que em 2007 foi substituído pelo Fundo de Manutenção e Desenvolvimento da Educação Básica e de Valorização dos Profissionais da Educação (FUNDEB), Lei ${ }^{\circ} 11.494 / 07$; d) a instituição de um Piso Salarial Profissional Nacional (PSPN), Lei $n^{\circ} 11.738 / 2008$, que estava na pauta de reivindicações da categoria docente brasileira desde 1988 . O tema da valorização docente constou também como uma das metas do Plano Nacional de Educação (PNE), Lei n ${ }^{\circ}$ 10.172/01, sendo reafirmada no PNE, Lei $\mathrm{n}^{\circ} 13.005 / 14$, especificamente em suas Metas 17 e 18 (LEHER, 2010).

Tais conquistas, no entanto, ainda não têm conseguido atender aos anseios da categoria docente na sua efetividade (BRITO, 2012; DUARTE; OLIVEIRA, 2014). Como exemplo, pode ser mencionado a Lei do PSPN, considerada um avanço parcial no campo da valorização, visto que a sua existência é positiva. Contudo, o valor final estipulado como piso salarial - determinado por uma carga horária de 40h, assegurando-se na jornada de trabalho apenas um terço para atividades extraclasse - e a não referência à formação dos profissionais em Ensino Superior foram considerados grande retrocesso (LEHER, 2010). Dentre os motivos do retrocesso, está a abertura de precedentes para as gestões municipais realizarem concurso tendo como exigência a formação em Ensino Médio, bem como para flexibilizar a carga horária semanal definida em 20 ou 30 horas para aqueles com Ensino Superior, fazendo o pagamento proporcional, ao invés do piso integral.

2 Direito suprimido pelo então presidente Fernando Henrique Cardoso, a partir da Emenda Constitucional (EC) nº 19/98, e readmitido no governo de Luís Inácio da Silva por meio da EC n ${ }^{\circ}$ 53/06, que dispõe sobre o FUNDEB (LEHER, 2010).

3 Lei de Diretrizes e Bases da Educação Nacional. 
Em pesquisa realizada por Alves e Pinto (2011) sobre o rendimento médio mensal de algumas profissões integrantes do agrupamento definido pelo IBGE $^{4}$ como "profissionais das ciências e das artes" e "técnicos de nível médio", a melhor colocação na docência da educação básica fica com as professoras do Ensino Médio, ocupando o $20^{\circ}$ lugar numa escala de 47 profissões. Em seguida, estão as do Ensino Fundamental séries finais com a $27^{a}$ posição; depois, vêm as do Ensino Fundamental séries iniciais com a $31^{\text {a }}$. Por fim, encontram-se as professoras da Educação da Primeira Infância na $36^{\mathrm{a}}$ posição.

Sobre a diferenciação salarial, cabe frisar que uma de suas causas está no tipo de vínculo de trabalho (concursado, temporário, substituto) e no amparo, ou não, em um plano de cargos e salários. Ademais, os aumentos salariais acabam por considerar mais o tempo de serviço do que outros quesitos, como formações continuadas. As análises realizadas por Oliveira e Vieira (2012) constatam que as gestões municipais têm recorrido a uma maior flexibilização nas relações de emprego, por meio dos contratos temporários de trabalho, como forma de burlar a implementação das obrigações da Lei do PSPN.

Observa-se também que, além do delineamento final da lei não atender ao que se esperava, a situação agrava-se quando se trata de sua efetivação, consoante dados da CNTE de 2016 (BRASIL, 2016), dos 27 estados da federação, apenas 14 afirmam cumprir o valor estipulado para início de carreira, cinco disseram que pagam proporcionalmente, e oito não cumprem a lei. Outrossim, quando se trata do cumprimento da jornada extraclasse, que estipula um terço da carga horária para planejamento, 19 estados afirmam cumprir, e oito, não.

O estado do Tocantins aparece entre os que cumprem integralmente a lei no quesito pagamento do valor estipulado, mas apresenta uma adesão de apenas $40 \%$ sobre o item composição da jornada de trabalho. Entendemos, à luz dessa constatação, o comentário frequente entre as docentes entrevistadas, que intitulam a Lei do Piso como a "Lei do Teto Salarial", ou seja, o que deveria ser entendido como um padrão de remuneração inicial da carreira acaba por se tornar, em muitos casos, no valor máximo percebido.

De acordo com Pinto (2009), o país pouco avançou, de 1827 para cá, na perspectiva de valorização dos professores, especialmente quando se fala de remuneração. Para o mesmo autor, há três critérios que determinam um padrão de remuneração dos docentes inferior ao de outras profissões de formação equivalente, são eles: "o poder público ser o maior empregador, portanto a remuneração está ligada à receita pública per capita; a capacidade de mobilização da categoria profissional e o prestígio da profissão, que se liga ao perfil do usuário" (PINTO, 2009, p. 59). Desse modo, a efetivação de um aumento salarial

4 Instituto Brasileiro de Geografia e Estatística. 
que equiparasse a remuneração docente com as de outras carreiras (Meta 17 do atual PNE) seria totalmente possível no campo da realidade tributária, mas sua consecução requer mudanças no campo político, que passa pelo reconhecimento social e valorização efetiva da profissão (PINTO, 2009).

Os estudos realizados por autores brasileiros como Alves e Pinto (2011), Campos, Esposito e Gimenes (2014), Duarte e Oliveira (2014), Gatti e Barreto (2009), Hypolito (2012) e Pinto (2009), dentre outros, colocam a carreira e a remuneração como uma variável fundamental no momento da escolha da profissão e afirmam que ela se configura como uma das estratégias para atrair e manter bons profissionais na profissão. De forma recorrente, a carreira e a remuneração também são apontadas como a causa da queda de matrículas nos cursos de licenciatura, do abandono do magistério e do absenteísmo docente. Para Hypolito (2012, p. 214), “[...] as condições de trabalho atuais têm a ver com a precarização, que tem a ver com intensificação, que tem a ver com autointensificação, que tem a ver com valorização do trabalho docente". Portanto, configuram-se como aspectos indissociáveis e que precisam ser assim tratados no momento da efetivação das políticas públicas.

\section{As condições de trabalho na Educação da Primeira Infância: desafios encontrados}

Na pesquisa realizada em 31 instituições escolares que atendem a primeira infância, tanto na área urbana quanto na área rural, foi avaliada a existência de 15 itens referentes às questões estruturais, entre eles: quadras esportivas, banheiros para as crianças e para os docentes, biblioteca, parquinhos de recreação, brinquedos, materiais pedagógicos, sala de professores etc.

Dos 15 itens avaliados, 9 apresentaram índices acima de 50\% na somatória das escalas regular e ruim. Isso revela que ainda estão aquém do que seria o ideal para um trabalho de qualidade.

Grosso modo, para $83,8 \%$ dos sujeitos docentes, destaca-se negativamente a disponibilidade de brinquedos que respondam aos interesses das crianças em quantidade suficiente, para diversos usos. Seguindo esse viés negativo, na opinião de $73,5 \%$ está a disponibilidade de materiais pedagógicos e audiovisuais que incentivem o conhecimento e o respeito à diversidade. Em terceiro lugar, também avaliados negativamente, $62,9 \%$ percebem os espaços e equipamentos acessíveis para acolher as crianças com necessidades especiais. Em quarto lugar, recebem o mesmo percentual negativo $(58,9 \%)$ a disponibilidade de materiais 
didáticos que permita trabalhar atividades de artes (barro, argila, tintas, massinha etc.) e as condições das áreas de recreação (parquinho, área verde externa, área coberta, quadra de esportes).

Diante dos itens avaliados negativamente, é possível considerar que fica comprometida a expectativa de oferta à criança de um espaço estimulante e propiciador de aprendizagens diversas, com representação de variadas linguagens, conforme orientam Barbosa e Horn (2008).

$\mathrm{Na}$ escala dos aspectos ruins, além dos já mencionados, estão as condições dos banheiros de funcionários, avaliados negativamente por $47,4 \%$ das entrevistadas. Vale mencionar que, em algumas escolas, eles compartilham os banheiros das crianças e, em uma escola visitada, sequer existia. Novamente, evidenciamos a ausência de uma política que de fato se preocupe em dar as condições mínimas para efetivação do trabalho docente.

Os aspectos que receberam melhor avaliação, na escala de excelente, não chegaram a $20 \%$ das respostas. Esses foram os seguintes: espaços para descanso e sono de bebês, iluminação e ventilação de sala de aula, condições da sala de professores, condição de conservação do prédio escolar (pintura, piso, teto, paredes etc.).

É preciso levar em consideração alguns itens. Espaços e equipamentos acessíveis para acolher as crianças com necessidades especiais e o espaço para descanso/sono dos bebês são uma realidade quase que exclusivamente das creches, em virtude de fazer parte dos requisitos para construção dos prédios. Esse fato explicita o porquê de $60 \%$ das docentes, principalmente da pré-escola e turmas multisseriadas/multietapas ${ }^{5}$, avaliarem como regular ou ruim os referidos itens. Encontramos uma escola de turma multisseriada/multietapa em que a gestora improvisou um espaço para o sono das crianças, por entender que essa é uma necessidade da faixa etária de 4 anos e mais.

Apreendemos que a visão mais positiva no espaço da creche liga-se ao fato de ser o segmento que contou com recursos do Proinfância ${ }^{6}$ e do Programa Brasil Carinhoso $^{7}$, o que representou significativo diferencial tanto em relação à estrutura predial (que não obteve nenhuma avaliação na escala ruim) quanto aos materiais disponíveis para desenvolvimento das atividades com as crianças

5 Denominamos de turmas multisseriadas/multietapas aquelas em que uma única docente, atende simultaneamente, no mesmo espaço, crianças da Educação Infantil e do Ensino Fundamental.

6 Programa Federal que foi criado em 2007 para a construção de unidades de Educação Infantil em parceria com os municípios.

7 Programa Federal que foi criado em 2012 para fazer a transferência automática de recursos financeiros para custear despesas com manutenção e desenvolvimento da Educação Infantil, contribuir com as ações de cuidado integral, segurança alimentar e nutricional, além de garantir o acesso e a permanência da criança na Educação Infantil. 
pequenas e os bebês. Ou seja, o espaço das creches, mesmo que apresentem inadequações, são aqueles que mais estão voltados para atender as especificidades da Educação na Primeira Infância, o que não ocorre frequentemente na maioria dos espaços de pré-escola e turmas multisseriadas/multietapas observados.

No caso da pré-escola, verifica-se que apenas quatro dos 15 itens receberam entre 50 a $40 \%$ de avaliação na escala "excelente ou bom". Nas turmas multisseriadas/multietapas, o resultado foi ligeiramente melhor, pois seis itens receberam de 60 a $40 \%$ de avaliação excelente ou boa.

Observamos uma correlação entre as inadequações na estrutura e o comportamento das crianças, que foi considerado ser o principal motivo do trabalho na Educação da Primeira Infância ser percebido como cansativo. Já se observou que

Permanecer oito horas numa creche ou numa pré-escola excessivamente quente ou fria; sem espaços adequados para brincar; com adultos sobrecarregados; sem área externa para correr, sem estímulo para saciar a curiosidade, à espera das rotinas é um sofrimento para qualquer um. (ROSEMBERG; ARTES, 2012, p. 179).

E esse sofrimento pode se traduzir em comportamentos de impaciência, mau humor e até agressividade por parte das crianças. Tal situação nos leva a indagar como fica a atenção individualizada nas turmas multisseriadas/multietapas que encontramos? Como se desdobrar para uma boa atenção a cada um em turmas de 20 a 25 crianças, algumas na faixa etária variando de 4 a 17 anos?

Essas situações reportam-se ao tema estudado por Rosemberg e Artes (2012) sobre o que chamaram de crianças fora do lugar, ou seja, crianças de Educação Infantil no Ensino Fundamental. Na área rural, esse percentual chegava a $60,5 \%$ das crianças, segundo as autoras citadas. Paradoxalmente, essa acaba sendo a alternativa mais viável para as crianças de 4 e 5 anos não ficarem fora da escola, já que identificamos rota de ônibus escolar com trajetória próxima aos $150 \mathrm{~km}$ para chegar em escolas onde há turmas específicas de Educação Infantil. Essa situação, portanto, leva alguns pais a retirarem suas crianças da instituição escolar, por receio de alguma fatalidade no trajeto, fato relatado por uma gestora de escola rural entrevistada em um dos municípios pesquisados.

Em publicação dos indicadores do trabalho docente na educação básica, resultante da pesquisa survey TDEBB/GESTRADO - Fase II, evidencia-se que há significativa relação estatística entre o grau de satisfação profissional com a percepção a respeito das condições de sala de aula, condições da unidade educacional e quantidade de alunos por turma. Isto é, o grau de satisfação 
profissional é diminuído ou elevado de acordo com a percepção de melhorias nas respectivas variáveis (OLIVEIRA et al., 2017).

Sabe-se que as condições de trabalho influem na saúde docente. Nesse sentido, buscamos saber dos sujeitos docentes se, por alguma vez, haviam se afastado do trabalho por licença médica. Os dados indicam que $46,9 \%$ já haviam se afastado do trabalho nos últimos 24 meses por algum problema de saúde. Os sujeitos que atuam na pré-escola apresentaram o maior percentual $(22,6 \%)$, seguidos pelo multisseriado/multietapa $(18,8 \%)$ e creche $(17,6 \%)$.

Dentre os motivos apontados para os afastamentos, os dois mais frequentes na creche foram as doenças musculoesqueléticas $(25 \%)^{8}$ e cirurgias diversas (25\%). Diferentemente do que poderíamos supor, os problemas de voz não tiveram significativa incidência entre as doenças relatadas, representando apenas $8,3 \%$ dos casos de afastamentos, sendo reportado apenas por docentes da pré-escola.

Em relação às condições de emprego, notamos que, no geral, há mais sujeitos docentes concursados $(63,5 \%)$ do que contratados (36,6\%). Das docentes estatutárias/concursadas, $51,1 \%$ disseram estar contempladas em um Plano de Cargos, Carreira e Remuneração (PCCR), enquanto 48,9\% responderam que não estavam contempladas. Das que responderam positivamente, 95,6\% afirmaram que é um plano pertencente à carreira do magistério. Três aspectos foram reconhecidos como os mais valorizados para fins de progressões: tempo de serviço (33\%), titulação (33\%) e participação em atividades de formação continuada $(25,9 \%)$.

Correlacionando-se as respostas "ser contemplada pelo PCCR" com "tempo de serviço das docentes", entendemos que algumas professoras, embora concursadas, ainda não são estáveis, o que ocorre somente após dois anos de efetivo exercício no cargo - o que justifica, em parte, as respostas negativas. Recordamos, ainda, a situação das 10 monitoras concursadas que não são consideradas professoras, por isso, não são regidas pelo PCCR.

Nesse sentido, a pesquisa de Guimarães, Hirata e Sugita (2012) revela que nas diversas sociedades, as práticas de cuidado geralmente estão ligadas à ideia de subalternidade, colocando as pessoas que a exercem em posição de inferioridade, especialmente no que se refere a um status social e profissional de suas ações. Dessa maneira, os profissionais que desenvolvem o cuidado/ care apresentam baixa qualificação, baixo reconhecimento de competências profissionais, ausência de especialização e dificuldades de autorreconhecimento, sendo uma atividade majoritariamente exercida por mulheres.

8 As lesões musculoesqueléticas referem-se a afecções que podem afetar os músculos, as articulações, os tendões, os ligamentos, os nervos, os ossos ou o aparelho circulatório. 
Correlacionando as condições de emprego com a avaliação que fazem sobre como se sentem em relação à estrutura de progressão profissional que a carreira proporciona, há um total de $48,8 \%$ que se considera "satisfeito ou muito satisfeito", e 47,7\% que está nos níveis de "insatisfeito ou muito insatisfeito".

Passando para outra correlação, agora com a questão salarial, verifica-se que o grau de satisfação com a carreira equipara-se com os valores dos vencimentos recebidos. Pois, as docentes de turmas multisseriadas/multietapas são as que possuem o maior percentual com faixa salarial de 3 a 4 salários mínimos (SM) $(31,3 \%)$, não havendo nenhuma referência ao recebimento de até $1 \mathrm{SM}$. $\mathrm{Na}$ creche, por sua vez, é onde se localiza o maior percentual daqueles que ainda recebem nessa faixa salarial (1 SM), equivalendo a $20,9 \%$ de seus profissionais, incluso aqui as monitoras não contempladas no PCCR. Quanto à pré-escola, é onde se observa o maior percentual de docentes na faixa salarial de 4 a $5 \mathrm{SM}$ $(13,2 \%)$, mas que fica em segundo lugar entre as que estão na faixa de 1 a 2 SM.

Como último aspecto relativo à dimensão das condições de trabalho enquanto valorização docente, destacaremos os dados referentes à formação continuada. Primeiramente, buscou-se saber se os sujeitos docentes haviam frequentado nos últimos dois anos algum curso de formação continuada. Nesse caso, $81,7 \%$ das professoras e $57,1 \%$ das monitoras responderam positivamente. O segmento com maior percentual positivo foi o multisseriado/multietapa $(93,8 \%)$, seguido da pré-escola $(76,9 \%)$ e por último a creche $(75 \%)$.

Os sujeitos docentes pesquisados avaliam, ainda de forma positiva, que, quando oferecidas, as formações continuadas contribuem para aprofundar o conhecimento sobre infância e sobre a prática de Educação Infantil, sobre inclusão de crianças com necessidades especiais entre outros aspectos referentes ao trabalho docente na Educação Infantil.

\section{Considerações finais}

A Educação Infantil no norte do Tocantins se caracteriza pela oferta eminentemente pública e urbana, onde mais de $50 \%$ dos estudantes se denominam negros. Predomina o atendimento às crianças de 4 e 5 anos de idade e uma estrutura organizativa em três segmentos: creche, pré-escola e turmas multisseriadas e multietapas. Não há creches no meio rural.

O número de creches é insuficiente diante da demanda existente, sendo encontrado vários prédios no modelo Proinfância em fase de conclusão, mas que 
estão com suas construções paralisadas devido à falta de recursos para terminá-los. Esse fato foi analisado por uma das secretárias municipais entrevistadas como resultante de um descompasso entre os cronogramas físico e financeiro das obras.

É importante frisar que, embora tenhamos encontrado uma quantidade maior de escolas localizadas na área rural, o índice de matrículas e o número de docentes é maior na área urbana. Tal situação se explica pela existência de turmas multisseriadas, com uma variação para multietapa; ou seja, turmas onde eram atendidas conjuntamente, por um único sujeito docente, crianças da pré-escola ao $5^{\circ}$ ano do Ensino Fundamental.

O contexto analisado mostra que a expansão do atendimento a qualquer custo compromete a qualidade da Educação e as condições para o exercício da docência. Ao profissional responsável pelo processo educativo das crianças devem estar garantidas condições básicas, como, por exemplo, um espaço reservado para planejamento e estudos, bem como ter acesso a um banheiro próprio. Tendo em vista que o espaço físico não é apenas um meio de educar, ele carrega inerente a si uma concepção de educação (BRASIL, 2006).

Quanto às condições em que essas atividades são exercidas, a estrutura disponível não atende satisfatoriamente aos critérios de uma Educação para a Primeira Infância de qualidade. As respostas obtidas nos levam a dizer que a creche é o espaço que mais respeita as especificidades da faixa etária atendida, mesmo com os déficits de infraestrutura e materiais didáticos pedagógicos apontados. Por sua vez, a pré-escola e as turmas que funcionam no meio rural são as mais impactadas quanto a esse quesito.

A respeito da estrutura da carreira docente dos sujeitos pesquisados, averiguou-se que mais de $60 \%$ são concursados e que $48 \%$ das professoras que estão nessa categoria consideram que são contempladas por um PCCR - o mesmo que traz como primeiro critério de progressão a questão do tempo de serviço, seguido pela titulação e, por último, a participação em formações continuadas.

Vale ressaltar que, quando se observa a realidade pelo viés dos segmentos, nota-se que a pré-escola e as turmas multisseriadas/multietapas são as mais atingidas pelas condições precárias de trabalho.

Diante dos dados coletados, verificou-se haver uma correlação entre aspectos relativos à remuneração e à garantia de algumas condições, tais como o controle sobre as atividades desenvolvidas, o tempo para atividades extraclasse dentro da carga horária de trabalho, a oferta de formações continuadas como elementos importantes, dentro da perspectiva de valorização do trabalho docente.

Em suma, o contexto descrito remete-nos a avaliar que, mesmo reconhecendo que nas últimas décadas houve avanços em relação às condições de trabalho - tanto no que se refere a sua dimensão estrutural quanto nas relações 
de trabalho -, a consecução de uma Educação da Primeira Infância comprometida com a qualidade da educação e o bem-estar das crianças e profissionais, ainda não se consolidou no sentido de implementar uma política sistemática de investimentos nas condições de trabalho oferecidas aos profissionais que educam e cuidam nas creches e pré-escolas. Políticas efetivas deveriam proporcionar, por exemplo, a materialização dos princípios básicos da carreira do magistério, que já constam nos Planos de Cargos Carreira e Remuneração (PCCRs) dos municípios (piso salarial profissional, aperfeiçoamento profissional, condições adequadas de trabalho, instalações e materiais didáticos adequados etc.), para todos os sujeitos docentes.

\section{REFERÊNCIAS}

ALVES, T.; PINTO, J. M. de R. Remuneração e características do trabalho docente no Brasil: um aporte. Cadernos de Pesquisa, 41 (143), p. 606-639, maio/ago. 2011.

BARBOSA, M. C. S.; HORN, M. da G. S. Projetos Pedagógicos na Educação Infantil. Porto Alegre: Artmed, 2008.

BERTOLDO, E.; SANTOS, M. Trabalho docente e luta de classes. In: BERTOLDO, E.; MOREIRA, L. A. L.; JIMENEZ, S. (orgs.) Trabalho, Educação e formação humana: frente à necessidade histórica da revolução. São Paulo: Instituto Lukács, 2012.

BRASIL. Lei n. 9.394, de 20 de dezembro de 1996. Dispõe sobre as Diretrizes e Bases da Educação Nacional. Brasília, DF, 1996. Disponível em: https://www2.camara.leg.br/ legin/fed/lei/1996/lei-9394-20-dezembro-1996-362578-publicacaooriginal-1-pl.html. Acesso em 29 mar. 2017.

. Lei n. 9.424, de 24 de dezembro de 1996. Dispõe sobre o Fundo de Manutenção e Desenvolvimento do Ensino Fundamental e de Valorização do Magistério, na forma prevista no art. $60, \S 7^{\circ}$, do Ato das Disposições Constitucionais Transitórias, e dá outras providências. Brasília, DF, 1996. Disponível em: http://www.planalto.gov.br/ccivil_03/ LEIS/L9424.htm. Acesso em: 29 mar. 2017.

. Lei n. 10.172, de 9 de janeiro de 2001. Aprova o Plano Nacional de Educação e dá outras providências. Brasília, DF, 2001. Disponível em: http://www.planalto.gov. br/ccivil_03/leis/leis_2001/110172.htm. Acesso em 29 mar. 2017.

. Ministério da Educação. Secretaria da Educação Básica. Parâmetros nacionais de qualidade para a educação infantil. Brasília: 2006. 2 v. 
. Lei n. 11.494, de 20 de junho de 2007. Regulamenta o Fundo de Manutenção e Desenvolvimento da Educação Básica e de Valorização dos Profissionais da Educação - FUNDEB, de que trata o art. 60 do Ato das Disposições Constitucionais Transitórias; altera a Lei n o 10.195, de 14 de fevereiro de 2001; revoga dispositivos das Leis n os 9.424, de 24 de dezembro de 1996, 10.880, de 9 de junho de 2004, e 10.845, de 5 de março de 2004; e dá outras providências. Brasília, DF, 2007. Disponível em: http://www. planalto.gov.br/ccivil_03/_ato2007-2010/2007/lei/111494.htm. Acesso em: 29 mar. 2017.

. Lei n. 11.738, de 16 de julho de 2008. Regulamenta a alínea "e" do inciso III do caput do art. 60 do Ato das Disposições Constitucionais Transitórias, para instituir o Piso Salarial Profissional Nacional para os profissionais do magistério público da educação básica. Brasília, DF, 2008. Disponível em: http://planalto.gov.br/ccivil_03/_Ato20072010/2008/Lei/L11738.htm. Acesso em: 29 mar. 2017.

. Lei n. 13.005, de 25 de junho de 2014. Aprova o Plano Nacional de Educação PNE e dá outras providências. Brasília, DF, 2014. Disponível em: http://www.planalto. gov.br/ccivil_03/_ato2011-2014/2014/lei/113005.htm. Acesso em 29 mar. 2017.

. Confederação Nacional dos Trabalhadores em Educação (CNTE). Tabela Salarial. 2016. Disponível em: http://www.cnte.org.br/index.php/tabela-salarial.html. Acesso em: 24 mar. 2017.

. Ministério da Educação. Instituto Nacional de Estudos e Pesquisas Educacionais (INEP). Sinopse estatísticas da Educação Básica: 2016. Brasília, DF: MEC/INEP, 2017. Disponível em: http://www.inep.gov.br. Acesso em: 20 jul. 2017.

BRITO, V. L. F. A. de. A remuneração dos profissionais da educação e dos desafios atuais. In: OLIVEIRA, D. A.; VIEIRA, L. F. (orgs.) Trabalho na Educação Básica: a condição docente em sete estados brasileiros. Belo Horizonte: Fino Traço, 2012.

CAMPOS, M. M.; ESPOSITO, Y. L.; GIMENES, N. A. S. A meta 1 do Plano Nacional de Educação: observando o presente de olho no futuro. Revista Retratos da Escola, Brasília, v. 8, n. 15, p. 329-352, jul./dez. 2014. Disponível em: http://retratosdaescola. emnuvens.com.br/rde/article/viewFile/445/576. Acesso em: 6 dez. 2016.

CODO, W. Educação: carinho e trabalho. Petrópolis: Vozes; Brasília: CNTE, Universidade de Brasília, Laboratório de Psicologia do Trabalho, 1999.

DUARTE, A. W. B.; OLIVEIRA, D. A. Valorização profissional docente nos sistemas de ensino de Minas Gerais e Pernambuco. Práxis Educacional, Vitória da Conquista, v. 10, n. 17, p. 67-97, jul./dez. 2014. Disponível em: http:/www.gestrado.net.br/images/ publicacoes/92/AlexandreDalila_ValorizacaoProfissionalDocenteMGePE.pdf. Acesso em: 22 jan. 2015.

ENGUITA, M. F. A la busca de un modelo profesional para la docencia: ¿liberal, burocrático o democrático? Revista Ibero-americana de Educación, 25, p. 43-64, ene/abr. 2001.

FREITAS, L. C. de. A reforma empresarial da educação: nova direita, velhas ideias. São Paulo: Expressão Popular, 2018. 
GATTI, B. A.; BARRETO, E. S. de S. (Coord.). Professores do Brasil: impasses e desafios. Brasília: UNESCO, 2009.

GESTRADO. Grupo de Estudos Sobre Política Educacional e Trabalho Docente. Relatório de pesquisa. Trabalho docente na Educação Básica no Brasil - Fase II. Belo Horizonte: Universidade Federal de Minas Gerais. 2015.

GUIMARÃES, N. A.; HIRATA, H.S.; SUGITA, K. Cuidado e cuidadoras: o trabalho do care no Brasil, França e Japão. In: HIRATA, H. \& GUIMARÃES, N. A. Cuidado e cuidadoras: as várias faces do care. São Paulo: Atlas, 2012. pp. 79-102.

HYPOLITO, A. M. Trabalho docente na educação básica no Brasil: as condições de trabalho. In: OLIVEIRA, D. A.; VIEIRA, L. F. (orgs.). Trabalho na Educação Básica: a condição docente em sete estados brasileiros, Belo Horizonte, MG: Fino Traço, 2012.

JÁEN, M. J. Os docentes e a racionalização do trabalho em educação: elementos para uma crítica da teoria da proletarização dos docentes. Teoria \& Educação, Porto Alegre, n. 4, p. 74-90, 1991.

LEHER. R. Valorização do magistério. In: OLIVEIRA, D. A.; DUARTE, A. M. C.; VIEIRA, L. M. F. DICIONÁRIO: trabalho, profissão e condição docente. Belo Horizonte: UFMG/Faculdade de Educação, 2010. CDROM.

LUDKE, M.; BOING, L. A. Caminhos da profissão e da profissionalidade docentes. Educação \& Sociedade, Campinas, v. 25, n. 89, p. 1159-1180, set./dez. 2004.

OLIVEIRA, D. A. Os trabalhadores da educação e a construção política da profissão docente no Brasil. Educar em Revista, Editora da Universidade Federal do Paraná, Curitiba, Brasil, n. 1, p. 17-35, 2010.

. A reestruturação da profissão docente no contexto da nova gestão pública na América Latina. Revista FAEEBA - Educação e Contemporaneidade, Salvador, v. 27, n. 53, p. 43-59, set./dez. 2018.

; ASSUNÇÃO, A. A. Condições de trabalho docente. In: ; DUARTE, A. M. C.; VIEIRA, L. M. F. DICIONÁRIO: trabalho, profissão e condição docente. [CD-ROM]. Belo Horizonte: Universidade Federal de Minas Gerais/Faculdade de Educação, 2010.

; VIEIRA, L. F. (orgs.). O trabalho na educação básica: a condição docente em sete estados brasileiros. Belo Horizonte: Fino Traço, 2012.

et al. Indicadores do trabalho docente na Educação Básica. Belo Horizonte/ MG: Fino Traço, 2017.

PINTO, J. R. Remuneração adequada do professor: desafio à educação brasileira. Revista Retratos da Escola, 3 (4), p. 51-67, jan./jun. 2009.

POPKEWITZ, T. S. Reforma Educacional: uma política sociológica. Porto Alegre: Artes Médicas, 1997. 
ROSEMBERG, F.; ARTES, A. O rural e o urbano na oferta de educação para crianças de até 6 anos. In: BARBOSA, M. C. S. et al. Oferta e demanda de educação infantil no campo. Porto Alegre: Evangraf, 2012.

TENTI FANFANI, E. Consideraciones sociológicas sobre profesionalización docente. Educação \& Sociedade, Campinas, v. 28, n. 99, p. 335-353, maio/ago. 2007.

VERGER, A.; NORMAND, R. Nueva gestión pública y educación: elementos teóricos y conceptuales para el estudio de un modelo de reforma educativa global. Educação \& Sociedade, Campinas, v. 36, n. 132, p. 599-622, jul./set. 2015.

VIEIRA, A. B. C.; ROCHA, M. O. da C.; GAMA, A. C. C.; GONÇALVES, D. U. Fatores causais e profilaxia da disfonia na prática docente. Cadernos de Educação, FaE/PPGE/ UFPel, Pelotas, n. 28, p. 255-270, jan./jun. 2007.

VIEIRA, L. M. F. V.; OLIVEIRA, D. A. Pesquisa trabalho docente na educação básica no Brasil: sinopse do survey nacional referente à educação infantil. Belo Horizonte: Universidade Federal de Minas Gerais, Grupo de Estudos Sobre Política Educacional e Trabalho Docente (GESTRADO), 2013.

Texto recebido em 04/06/2019. Texto aprovado em 15/10/2019. 